\title{
Web-Based Learning as a Tool of Knowledge Continuity
}

\author{
Saiful Hafizah Jaaman ${ }^{1}$, Rokiah Rozita Ahmad ${ }^{1} \&$ Azmin Sham Rambely ${ }^{1}$ \\ ${ }^{1}$ School of Mathematical Sciences, Faculty of Science and Technology, Universiti Kebangsaan Malaysia, \\ Selangor, Malaysia \\ Correspondence: Saiful Hafizah Jaaman, School of Mathematical Sciences, Faculty of Science and Technology, \\ Universiti Kebangsaan Malaysia, 43600 UKM Bangi, Selangor, Malaysia. Tel: 60-389-213-422. E-mail: \\ shj@ukm.my
}

\author{
Received: February 7, 2013 Accepted: March 25, 2013 Online Published: May 13, 2013 \\ doi:10.5539/ies.v6n6p80 \\ URL: http://dx.doi.org/10.5539/ies.v6n6p80
}

\begin{abstract}
The outbreak of information in a borderless world has prompted lecturers to move forward together with the technological innovation and erudition of knowledge in performing his/her responsibility to educate the young generations to be able to stand above the crowd at the global scene. Teaching and Learning through web-based learning platform is a complementary method of conventional teaching and learning approaches which has a lot of potential to produce a more meaningful learning experience. In the School of Mathematical Sciences of Universiti Kebangsaan Malaysia, courses such as Basis Accounting and Finance have begun to employ web-based learning website known as Connect provided by the book publisher McGraw-Hill. This paper discusses the importance of cultivating teaching and learning through such formal website as a useful tool of providing learning experiences to students in the process of enhancing students' knowledge retention thus improve their academic performances. In this paper, students' performances in the academic session prior to introduction of web-based learning where only traditional and e-learning approaches are used is investigated and compared to performances of students employing web-based learning in addition to the traditional and e-learning methods. Findings of this paper found that students' performances, specifically students whom are considered as 'weak', improve when web-based learning is introduced.
\end{abstract}

Keywords: blended learning, e-learning, knowledge retention, performance, traditional learning

\section{Introducation}

The speedy development in information and communication technologies has inspired attempts towards integrating web-based learning (WBL) activities into the teaching and learning process. Advances in technology lead to the demand for applying technological tools to enhance teaching and learning. One of the latest innovations is the web-based learning activities which among others involve information searching tasks, online teaching and learning, also role-plays and simulations. WBL has various advantages. For instance it does not only benefit students studying at a distance but also offer a range of learning opportunities for full-time students whom may need help to increase their commitment to learning. Nowadays, rote learning is no longer sufficient to alleviate students' understanding in learning a certain subject or concept. According to Angell et al. (2004) a good lesson is one that offers variations. Instead of educational practices using chalk and talk which students considered as boring, lessons with active participation using approaches that involved more opportunities for interaction and discussions are preferred.

A learning program where more than one delivery mode is being used to promote learning and skill acquisitions aiming to optimize the learning outcome is known as blended learning (BL) (Akkoyunlu and Soylu 2008, Deng and Yuen 2009, Yuen 2011). BL is the integration of multiple learning techniques and strategies into one learning system, for instance the integrating of software applications, web-based courses, face-to-face learning, live e-learning and self-paced learning (Singh 2003). Thus, the combination of WBL and traditional learning method such as the face-to-face interaction is categorized as blended learning. Alebaikan (2012) investigated students' acceptance towards combination of teaching and learning $(T \& L)$ methods concluded that majority of university students were eager to enroll in such learning. Cucciare et al. (2003) suggested that blended learning is a fitting way to tailor the learning process to the needs of the students by integrating the innovative and technological improvements offered by online learning with the interaction and participation offered by the traditional learning. The incorporation of WBL and traditional learning environments ideally combined the benefits of both 
approaches where WBL environments provide the flexibility which may not be found in a classroom environment while face-to-face learning environment ensures the social interaction which is required for learning. As stated by Tham and Tham (2011), learning process which combines more than one delivery method allows both instructor and student effective and continuous educational experiences as compared to only using face-to-face instruction.

Web-based learning is a tool for knowledge continuity. It provides more opportunities for instructor-student interaction, increased student's commitment and enhanced teaching and learning environment. WBL facilitates in fulfilling knowledge gaps students discover by providing the resources where students can utilize to satisfy their knowledge hunger. Web-based type of learning can reach out to large numbers of students quickly with information that can be tailored to the needs of the learners. Compared to solely traditional classroom learning, combining multiple learning strategies such as integrating between traditional learning and WBL can improve both students knowledge of the subjects learned and information retention more than $100 \%$ (Cucciare et al. 2003). Wu et al. (2010) examined students' learning satisfactions in a blended e-learning system environment found that learning climate such as computer self-efficacy significantly affected learning satisfaction and performance.

This study complements and contributes to the existing literature. In this study, the investigation is focused on observing students' performances on final examinations guided by the following research questions: What are the grades students' received in the two different teaching and learning methods employed? How are students' final examinations performances from the two different T\&L methods differ? The study examines a course coordinated by the same instructor who has more than ten years experience managing the course.

\section{Method}

\subsection{The Designated Course}

In this study, students' performances in the final examination for the course, Basic Accounting and Finance, in two separate academic sessions, academic session 2010/2011 and academic session 2011/2012, are investigated and compared to determine whether different T\&L methods affect students' performances. This course is a compulsory course imposed by the School of Mathematical Sciences at Universiti Kebangsaan Malaysia (UKM). In order to be conferred one of the three Bachelor of Science degrees offered by the School; Mathematics, Statistics or Actuarial Science, students are required to pass this course.

The course, Basic Accounting and Finance, is offered in the $1^{\text {st }}$ Semester of each academic session and is placed under the management of the Actuarial Science program. It is an introductory course which explores the basic structures and concepts of accounting emphasizing on the preparation and understanding of the financial statements and financial statement analyses. The course is supposed to familiarize students with accounting terminology, the language requires for the students to understand business communications. The course is taught by the lecturer who introduced and designed its syllabus for the School curriculum. The lecturer is an academic member of the School with more than 10 years experience coordinating the course. In both academic sessions investigated in this study, the same text book published by McGraw-Hill is used.

\subsection{Students' Background}

As the designated course is a compulsory course to all students in the School regardless of whether they are Mathematics, Statistics or Actuarial Science majors, in each academic session there are more than 100 students registered in the course. The only difference is that students majoring in Mathematics and Statistics take the course in their $3^{\text {rd }}$ year while the Actuarial Science majors sign up for the course in their sophomore year. In each academic session, the School offers to about forty students for placement in each of the three academic programs, thus students' distribution according to program are fairly equal.

In the academic session prior to registering in this course, Basic Accounting and Finance, the same group of students took two Economic courses which are also stipulated as compulsory by the School; Micro Economics in the $1^{\text {st }}$ semester while in the $2^{\text {nd }}$ semester students took Macro Economics. Similar to Basic Accounting and Finance, the Economics courses are managed by the Actuarial Science program but are taught by two separate instructors.

\subsection{Teaching and Learning Methods Employed}

Previously before the academic session 2011/2012, the T\&L methods employed by the lecturer coordinating the course composed of two approaches, the traditional T\&L of face-to-face interaction and e-learning. The face-to-face interaction was by means of three hours lecture per week for roughly about 14 weeks in the semester. The three hours lecture was divided to two hours lecture on Thursday and another hour on Friday. In addition, 
course syllabus and weekly notes were posted in the e-learning system created specifically for the course which was provided and maintained by the university. Students were encouraged to attempt the problems given at the end of each chapter in the text book. Throughout the semester, written assignments on problems from the chapters in the textbook were given on a regular interval which would be graded by the instructor. Though answers to the assignments were posted in e-learning immediately a day after the assignment due date, instructor needed time to grade more than 100 assignments, thus students were not able to know how they fared in each assignment instantly.

To facilitate the instructor in evaluating loads of assignments, since the academic session 2011/2012 web-based learning has also been embedded in the course in addition to face-to-face lecture and e-learning. The weekly three hours lecture on Thursday and Friday and posting of course syllabus and weekly notes in the e-learning system continue. Contrary to academic session 2010/2011, in academic session 2011/2012 weekly assignments from the chapters in the text book are given and done online using "Connect", a web-based assignment and assessment platform provided by the text book publisher, McGraw-Hill. As stated in its website, McGraw-Hill Connect fortifies the link between lecturer, students and the course, helping students to be more engaged in the course so that they are better prepared, retained more knowledge and hopefully achieve better results. For each task assigned in Connect, lecturers may set rigid or flexible policies. For example, lecturers may be rigid by setting policies that limit students' attempts, not allowing students assess to e-resources and hints. On the contrary, lecturers may set policies that are very flexible to allow the full benefits of learning through a web-based learning platform such as Connect. For lecturers, Connect helps grade students' assignments hence providing instant detailed feedback to students and reduce grading time for lecturers. Through Connect, lecturers are able to evaluate thoroughly each student understanding and performance for each assigned chapter as lecturers may view the full report on each student's performance for each assignment given. Table 1 below summarizes the T\&L approaches employed in both academic sessions.

Table 1. Teaching and learning approaches employed

\begin{tabular}{|c|c|c|}
\hline Item & Academic Session 2010/2011 & Academic Session 2011/2012 \\
\hline \multirow[t]{2}{*}{ Course Schedule } & Thursday, $11.00-1.00 \mathrm{pm}$ & Thursday, $11.00-1.00 \mathrm{pm}$ \\
\hline & Friday, $8.00-9.00 \mathrm{am}$ & Friday, $8.00-9.00 \mathrm{am}$ \\
\hline Lecturer \& Text book & $\begin{array}{l}\text { Course conducted by the same } \\
\text { lecturer \& using the same text book }\end{array}$ & $\begin{array}{l}\text { Course conducted by the same } \\
\text { lecturer \& using the same text book }\end{array}$ \\
\hline No. of Students & 162 & 125 \\
\hline Evaluation & $\begin{array}{l}\text { Compose of Final Examination and } \\
\text { Written Assignments (graded by } \\
\text { the lecturer) }\end{array}$ & $\begin{array}{l}\text { Compose of Final Examination and } \\
\text { Web-based Assignments (graded } \\
\text { electronically) }\end{array}$ \\
\hline Teaching and Learning Methods & Face-to-face lecture and e-learning & $\begin{array}{l}\text { Face-to-face lecture, e-learning and } \\
\text { web-based learning }\end{array}$ \\
\hline
\end{tabular}

\subsection{The Final Examinations}

In both academic sessions, the final examination is formally scheduled by the Academic Education Centre of the university at the end of the semester. The final examination for Basic Accounting and Finance in both sessions lasts for two hours and thirty minutes. The examination questions are divided into two parts, part A is composed of 50 multiple choice questions and part B consists of three problem set questions. The examination questions in both sessions are basically similar with only minor modification, to make the examinations seem dissimilar the order of the questions in the final examination of the later are revamped. In both examinations the total mark is 100 points, 50 marks are from part A while another 50 marks are contributed by part B. Part A of the examination is graded electronically based on answers provided by the lecturer. Normally, lecturer is given two weeks to grade the problem set questions. In UKM, all final examination questions and solutions need to be vetted and verified by panel of evaluators chosen by each faculty, school and program.

\section{Results}

In this study, the final examination results of students taking the course Basic Accounting and Finance offered by the School of Mathematical Sciences, UKM in academic sessions 2010/2011 and 2011/2012 are investigated and 
compared. Beginning from academic session 2010/2011 the course has become a compulsory course to all students enrolling in the School. In both academic sessions the course is taught by the same lecturer and used the same text book. The only variation in the teaching and learning process between the two academic sessions is that in academic session 2011/2012, Connect, the web-based assignment and assessment platform provided by McGraw-Hill is made available and used extensively in the T\&L of the course. The students are given web-based assignments and do all the assignments online with these assignments assessed immediately after due date and feedback are provided to the students instantaneously. In addition, to ensure that students are able to execute the tasks, they are allowed to utilize all the resources made available in Connect. On average in both academic sessions, students did ten individual assignments, in academic session 2010/2011 students handed written assignments which were graded by the lecturer while for academic session 2011/2012 the assignments were given, done and graded online. At the end of the semester students took a schedule comprehensive final examination consisting of multiple choice and problem type questions that lasted for two and a half hours. Table 2 presents the descriptive statistics of the final examination results for both academic sessions.

Table 2. Descriptive statistics of final examinations results

\begin{tabular}{lll}
\hline Item & $\begin{array}{l}2010 / 2011 \\
(\%)\end{array}$ & $\begin{array}{l}2011 / 2012 \\
(\%)\end{array}$ \\
\hline Mean & 53.88 & 58.18 \\
Standard Deviation & 21.76 & 18.85 \\
Maximum & 97.00 & 98.00 \\
Minimum & 15.00 & 24.00 \\
No. of Input Data & 162 & 125 \\
\hline
\end{tabular}

There were 162 students taking the course in 2010/2011 while 125 students took it in academic session 2011/2012. As shown, the highest score in academic session 2011/2012 is only one point higher (98\%) than the highest score in academic session 2010/2011 (97\%), the lowest score for academic session 2010/2011 at 15\% fails the final exam (grade E) while the lowest score for academic session 2011/2012 which is $24 \%$ receives a grade D. The mean score for both sessions; $58.18 \%$ for $2011 / 2012$ and $53.88 \%$ for $2010 / 2011$ are in grade B-.

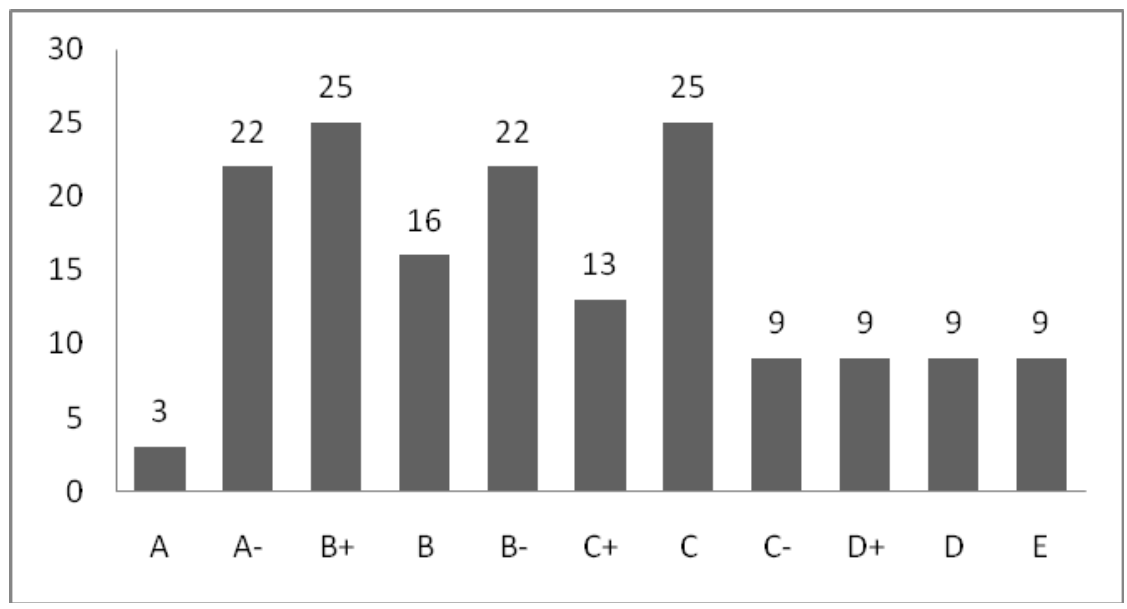

Figure 1. Analysis of final examination results for academic session 2010/2011 (no. of students)

Figure 1 gives the final exam detail results for academic sessions 2010/2011 while figure 2 gives the detail results for academic session 2011/2012 in terms of number of students. 


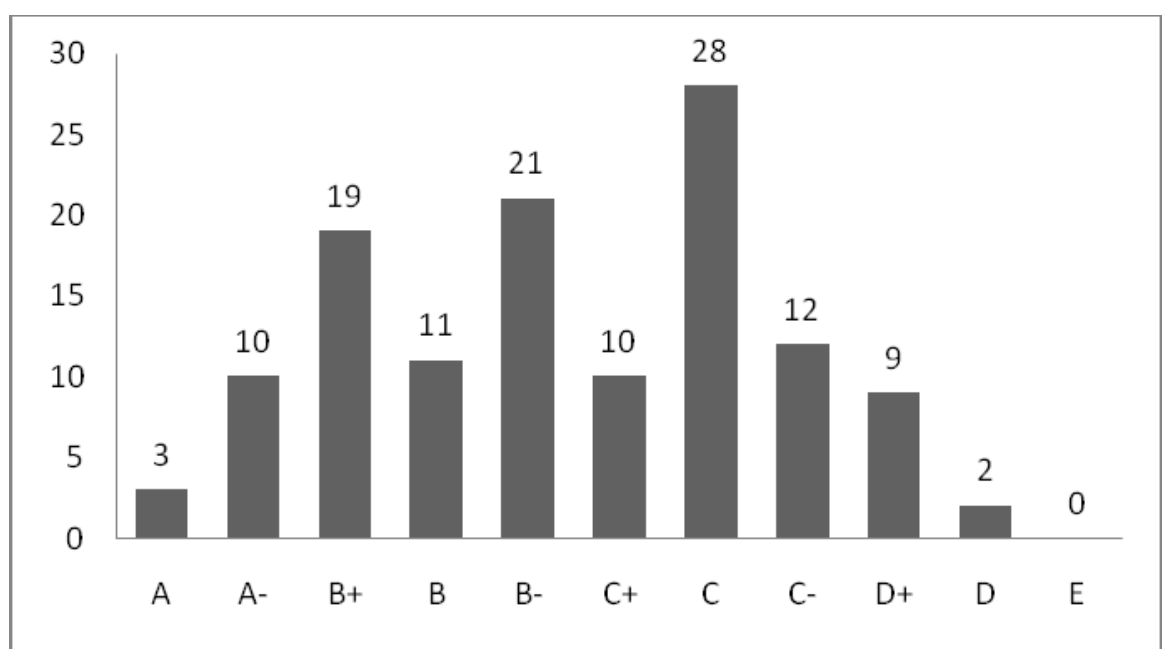

Figure 2. Analysis of final examination results for academic session 2011/2012 (no. of students)

As illustrated in figures 1 and 2, there are a number of nine students receive grade $\mathrm{D}+$ and two students receive a D in 2011/2012 as compared to nine students receive grade D+ and nine students fall in grade D in 2010/2011. None of the student fails the final examination in session 2011/2012 while nine students fail in 2010/2011. Three students receive a solid A grade in both sessions. Nevertheless there are 22 students receive grade A- in 2010/2011 while only 10 students are in the same grade in academic session 2011/2012. Twenty-five students get B+ in 2010/2011 as compared to only 19 students in 2011/2012.

Table 3. Analysis of final examinations results (\%)

\begin{tabular}{ccc}
\hline Grade & $\begin{array}{c}2010 / 2011 \\
(\%)\end{array}$ & $\begin{array}{c}2011 / 2012 \\
(\%)\end{array}$ \\
\hline A to A- & 15.00 & 10.00 \\
B+ to B- & 39.00 & 41.00 \\
C+ to C- & 29.00 & 40.00 \\
D+ to D & 11.00 & 9.00 \\
E & 6.00 & 0.00 \\
\hline
\end{tabular}

Table 3 contrasts the grade analysis for both academic sessions in percentage which provides a better comparison. Though the percentage of students receiving grade A to A- is higher in academic session 2010/2011 (15\%), 6\% fail the final exam and $11 \%$ receive grade $\mathrm{D}+$ to $\mathrm{D}$. In contrary, no student fails the final examination in academic session 2011/2012 and only $9 \%$ are in category D+ to D. In academic session 2011/2012 when the web-based learning environment is introduced via McGraw-Hill Connect, $91 \%$ of the students manage to secure a grade C- to A as compared to $83 \%$ of the students receive grade C- to A in academic session 2010/2011 before the availability of Connect.

\section{Conclusion}

The findings above present that web-based learning successfully assists students, specifically the low performance students, to retain more knowledge and as a result improve students' grades. A web-based learning platform helps students to become better learners. Web-based learning is a tool for knowledge continuity providing learners with multiple learning options which open up opportunities for more learning. Students learn on his/her own time and pace, regardless of students' learning style, each student can make web-based learning their own to achieve learning goals. This is particularly beneficial for courses with large number of students as it is challenging for the lecturer to apply student-focused learning approach. Having tools such as web-based learning which are flexible enough to fit into students' schedules thus is important for students today and definitely aid them to reinforce the knowledge receive during lectures. It is suggested that web-based learning to be fully implemented as a T\&L 
approach in all courses offered by the School as it fulfills and complements the needs of both students and lecturers.

\section{Acknowledgement}

The authors appreciate the support from the research grants: UKM-PTS-2011-035 and UKM-PTS-2012-094.

\section{References}

Akkoyunlu, B., \& Soylu, M. Y. (2008). A Study of Student's Perceptions in a Blended Learning Environment Based on Different Learning Styles. Educational Technology \& Society, 11(1), 183-193. ISSN 1436-4522 (online).

Alebaikan, R. A. (2012). The future of blended learning. International Journal of Agricultural and Environmental Engineering, 6, 56-60. ISSN 2010-3778 (online).

Angell, C., Guttersrud, Ø, Henriksen, E. K., \& Isnes, A. (2004). Physics: Frightful, but fun. Pupils' and teachers' views of physics and physics teaching. Science Education, 88(5), 683-706. http://dx.doi.org/10.1002/sce.10141

Cucciare, M. A., Weingardt, K. R., \& Villafranca, S. (2008). Using Blended Learning to Implement Evidence-Based Psychotherapies. Clinical Psychology: Science and Practice, 15(4), 299-307. http://dx.doi.org/10.1111/j.1468-2850.2008.00141.x

Deng, L., \& Yuen, H. K. (2009). Designing blended learning communities: Principles and implementation. In F. L. Wang, J. Fong, \& R. C. Kwan (Eds.), Handbook of research on hybrid learning models: Advanced tools, technologies, and application (pp. 228-243). Hershey, PA: IGI Global Publications. http://dx.doi.org/10.4018/978-1-60566-380-7

Singh, H. (2003). Building effective blended learning programs. Educational Technology, 43, 51-54. ISSN: 00131962

Tham, K. O., \& Tham, C. K. (2011). Blended learning - A focus study on Asia. IJCSI International Journal of Computer Science Issues, 8(2), 136-142. ISSN 1694-0814 (Online).

Thorne, K. (2003). Blended learning: How to integrate online and traditional learning. London: Kogan Page. ISBN-139780749450083.

Wu, J., Tennyson, R. D., \& Hsia, T. (2010). A study of student satisfaction in a blended e-learning system environment. Computers and Education, 55(1), 155-164. http://dx.doi.org/10.1016/j.compedu.2009.12.012

Yuen, A. H. K. (2011). Exploring teaching approaches in blended learning. Research and Practice in Technology Enhanced Learning, 6(1), 3-23. 